\title{
Correspondencia entre la dosis efectiva del cristalino calculada con dosímetro de tórax y dosímetro ocular
}

\author{
Jhoan Steven Díaz Henao'; María Camila Dávila Castañeda'. \\ Docente Asesora: Ángela María Rincón Hurtado², Carolina Gallego Londoño ${ }^{3}$
}

RESUMEN La dosis límite de radiación estimada para el cristalino es de $20 \mathrm{mSv}$ (International Commission on Radiological Protection). La dosis se puede medir de 2 formas: indirectamente mediante un dosímetro de tórax ubicado en el pecho (con cierta distancia desde donde se obtiene la dosis hasta la ubicación del órgano en estudio), ponderando la dosis obtenida para el cristalino; la segunda forma es de manera directa mediante el uso de un dosímetro ocular, ubicado cerca del órgano en estudio, brindando resultados directos.

Por lo anterior, se determinará la correspondencia entre la dosis efectiva del cristalino calculada con un dosímetro de tórax y la dosis medida con un dosímetro ocular, del personal de un centro de hemodinamia de la ciudad de Pereira, (Colombia), mediante un estudio longitudinal prospectivo y analítico, con un análisis estadístico de varianza para un solo factor de la variable respuesta.

\section{Cristalino;}

PALABRAS Efectos de Radiación; Radiación Ionizante;

Dosimetría;

Catarata.

1 Estudiantes del Programa de Tecnología en Radiología e Imágenes Diagnósticas de la Fundación Universitaria del Área Andina. Semillero GIRA.

2 Docente Asesora metodológica.

3 Docente Asesora temática. 


\section{Correspondence between the effective dose of the lens calculated with a chest dosimeter and an eye dosimeter}

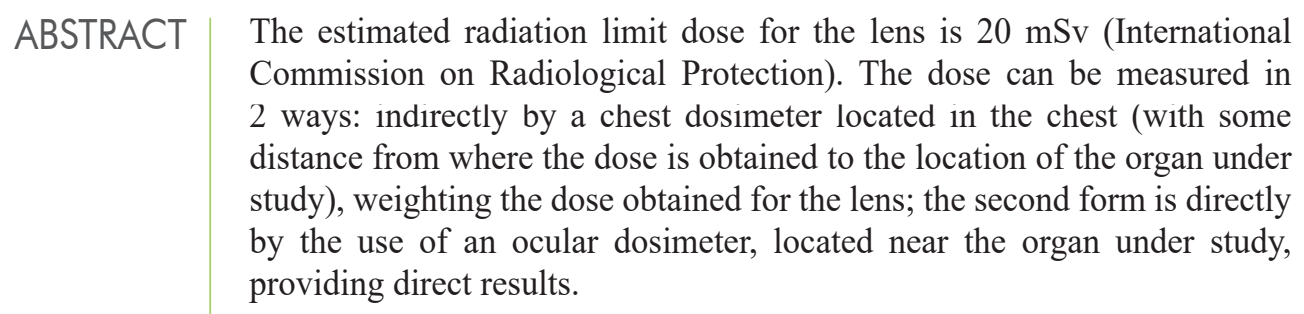

Therefore, the correspondence between the effective dose of the lens calculated with a chest dosimeter and the dose measured with an ocular dosimeter, of the staff of a hemodynamic centre in the city of Pereira, (Colombia) should be determined, using a prospective and analytical longitudinal study, with a statistical analysis of variance for a single response variable factor.

Crystalline;

Radiation Effects;

KEYWORDS Ionizing Radiation;

Dosimetry;

Cataract. 


\section{INTRODUCCIÓN}

Las observaciones realizadas por la Organización Internacional de Energía Atómica (OIEA), enfatizan que las personas que trabajan en las salas de radiología intervencionista (médicos intervencionistas, enfermeros, tecnólogos en radiología) permanecen próximos a la fuente de rayos $\mathrm{X}$ y al campo de radiación dispersa, durante largos periodos de tiempo, (2) dando lugar al desarrollo de diversas patologías, tales como efectos cancerígenos, tumores benignos, lesiones en la piel, cataratas, cefaleas entre otras.

Las cataratas se consideran como un efecto determinista, el cual se define como "aquél cuya gravedad depende de la dosis de radiación una vez se traspasa el umbral de dosis", razón por la cual la Comisión Internacional de Protección Radiológica (ICPR) junto con el Consejo Nacional de Protección Radiológica (NCPRP) de EEUU, dieron a conocer valores de umbrales que permiten establecer las dosis para opacidades detectables de $5 \mathrm{~Sv}$, absorbidos en exposiciones con periodos de tiempo largos, y de 0,5 a $2 \mathrm{~Sv}$ para exposición aguda, en nuestro contexto los dispositivos de protección radiológica específicos para el cristalino no se utilizan sistemáticamente, lo cual puede llegar a generar una alta exposición de los ojos del personal que trabaja en las salas de intervencionismo (2).

Una serie de estudios a nivel mundial, sugieren que puede haber un riesgo significativo de opacidad del cristalino en poblaciones expuestas a bajas dosis de radiación ionizante; estos estudios incluyen a personas que se someten a exploraciones de tomografía computarizada, astronautas, técnicos radiológicos y pacientes tratados con radioterapia, supervivientes de bombas atómicas y los expuestos en el accidente de Chernobyl (3).

Encuestas realizadas por la OIEA (Organización Internacional de Energía Atómica) en diversos cursos de capacitación, en las que fueron partícipes médicos cardiólogos de más de 56 países, arrojaron entre otras respuestas que solo el 33,77\% de los cardiólogos intervencionistas utilizan regularmente sus dosímetros, y fue este el motivo por el cual la OIEA inició en 2008 un estudio a nivel internacional llamado RELID (Evaluación Retrospectiva de las Lesiones del Cristalino y de las Dosis).

De acuerdo con esta declaración, el umbral de dosis absorbida en el cristalino del ojo actualmente es de 0,5 Gy. Las estimaciones indican que las dosis acumuladas que reciben los trabajadores ocupacionalmente expuestos durante su vida profesional pueden superar estas normas aceptadas internacionalmente, por lo cual en abril de 2011 la ICRP ha emitido una declaración, reduciendo el límite de dosis para el cristalino en casi 8 veces (3). 
Tabla 1.

Limites de dosis en 1990 y 2011.

\begin{tabular}{llll}
\hline Para el año 1990: & Para el año 2011: \\
\hline Tipo de límite & $\begin{array}{l}\text { Trabajador } \\
\text { ocupacionalmente } \\
\text { expuesto. }\end{array}$ & Tipo de límite & $\begin{array}{l}\text { Trabajador } \\
\text { ocupacionalmente } \\
\text { expuesto. }\end{array}$ \\
\hline Dosis efectiva & $\begin{array}{l}\text { 20 msv por año } \\
\text { promediada en períodos } \\
\text { definidos a 5 años. }\end{array}$ & Dosis efectiva & $\begin{array}{l}20 \text { msv por año } \\
\text { promediada en períodos } \\
\text { definidos a 5 años. }\end{array}$ \\
\hline $\begin{array}{l}\text { Dosis equivalente } \\
\text { anual en : }\end{array}$ & & $\begin{array}{l}\text { Dosis equivalente } \\
\text { anual en : }\end{array}$ & \\
$\begin{array}{l}\text { Cristalino } \\
\text { Manos y pies }\end{array}$ & $150 \mathrm{msv}$. & $\begin{array}{l}\text { Cristalino } \\
\text { Manos y pies }\end{array}$ & 20 msv. \\
\hline
\end{tabular}

Construcción propia.

En la Tabla No. 1, pueden observarse los valores de dosis umbral que la ICPR tenía contemplados para diferentes órganos, incluido el órgano del cristalino para el año 1990; valores de referencia para ese momento.

Siendo esta problemática un campo poco explorado en la medición de este riesgo a nivel nacional, un estudio realizado en el Hospital Pablo Tobón Uribe en la ciudad de Medellín (Colombia) en el año 2016 sobre la determinación de dosis para el cristalino, destaca la alarma por la aparición de lesiones radio inducidas en los ojos en el trabajador ocupacionalmente expuesto en hemodinamia y PET-CT, dando a conocer la importancia del uso de dosimetría directa e implementación de utilización de gafas plomadas para vigilancia y control de la exposición a radiaciones ionizantes, en el personal ocupacionalmente expuesto (4).

El personal que labora en los servicios de hemodinamia no utiliza las gafas protectoras, dado que la legislación colombiana que regula los elementos de radio protección a utilizar en los centros radiológicos no exige el uso de las mismas, convirtiéndose en un dispositivo de uso libre y no reglamentario, que por su considerable costo no es adquirido de modo particular por el personal.

Para el cristalino existen dos formas de obtener la dosis, de manera directa por medio de un dosímetro ocular y de manera indirecta por medio de un dosímetro de tórax, tomando la dosis obtenida por determinado periodo de tiempo, y calculada con el factor de ponderación tisular para el cristalino. 
Como estudiantes del área de la salud y futuros Tecnólogos en Radiología e Imágenes Diagnósticas, surge esta investigación pensando en el bienestar de cada trabajador ocupacionalmente expuesto, donde se busca dar a conocer la dosis efectiva que se está recibiendo, y comprobar que dicha dosis sea equivalente a la ponderada del dosímetro de tórax; de no ser así, brindar al personal la dosis real al que este órgano en particular está expuesto, generando conciencia y promoviendo el auto cuidado, la importancia de portar todos sus elementos de protección, conociendo lo que implica estar sometido a radiación ionizante, en este caso para un órgano en específico: el cristalino.

Los resultados obtenidos de esta investigación serán de gran utilidad para comunidades científicas, académicas y entes encargados de realizar la normatividad del uso de elementos de radioprotección en los servicios de intervencionismo (hemodinamia), e impactar en las políticas correspondientes.

Lo mencionado, nos lleva a determinar la correspondencia entre la dosis efectiva del cristalino calculada con un dosímetro de tórax, y la dosis medida con un dosímetro ocular, del personal ocupacionalmente expuesto en un centro de Hemodinamia de la ciudad de Pereira, 2019.

\section{MATERIALES Y MÉTODOS}

Estudio longitudinal prospectivo y analítico, que se realizó entre el 15 de marzo y el 15 de julio de 2019, en 12 trabajadores ocupacionalmente expuestos del servicio de hemodinamia en la ciudad de Pereira, a quienes se les determinó la correspondencia entre los valores de dosimetría obtenidos a partir del reporte de dosis efectiva para el cristalino, medida de manera indirecta a través de la ponderación tisular del dosímetro de tórax, y directa por medio de un dosímetro ocular.

Los dispositivos de medición los portaron Trabajadores Ocupacionalmente Expuestos que laboran en el área de Intervencionismo en una Institución Prestadora de Servicios de Salud de la ciudad de Pereira. Tanto el dosímetro ocular como el de tórax, leerán de manera mensual por el trascurso de 4 meses.

El análisis estadístico que se empleará es de varianza para un solo factor de la variable respuesta "dosis del cristalino", con el cual se determinará si las diferencias entre la medición 1 y la medición 2, complementándola con análisis de Tuckey de comparaciones múltiples, con el fin de determinar entre cuáles medidas existe diferencia, además de una distribución T de probabilidad para estimar la media, dado que el tamaño de la muestra es pequeño. 


\section{RESULTADOS}

Los resultados que se pretenden obtener de esta investigación, puesto que aún se encuentra en curso, son con el fin de generar información que sea de consulta en la comunidad académica y científica para una práctica segura; promover el auto cuidado con la implementación del uso de dosímetro ocular y de elementos de radioprotección interesados en un órgano en particular "el cristalino", como lo serían las gafas plomadas para el Trabajador Ocupacionalmente Expuesto a las radiaciones ionizantes, así como divulgar los resultados generados por la investigación, para que llegue a manos de los entes encargados de generar las políticas correspondientes del tema y que sea útil para una futura toma de decisiones, donde puedan promover medidas directas y seguras, aportar estos resultados para avances tecnológicos y nuevos proyectos de investigación que contribuyan a la salud, seguridad y bienestar de las personas con exposición ocupacional sostenida.

REFERENCIAS 1. Baños A. Bases físicas y biológicas del radiodiagnóstico médico [Internet]. 2. ${ }^{a}$ ed. Murcia U de, editor. Murcia; 2003. 102 p. Disponible en: https://books. google.com.co/books?id=mtQkRFUmhgsC\&printsec=frontcover\&hl=es\&sour $\mathrm{ce}=\mathrm{gbs}$ _ge_summary_r\&cad$=0 \# \mathrm{v}=$ onepage $\& \mathrm{q} \& \mathrm{f}=$ false

2. Agency IAE. Estudio del OIEA sobre las cataratas [Internet]. Actividad del OIEA sobre la Evaluación retrospectiva de las lesiones del cristalino y de las dosis (RELID). 2013 [citado 26 de febrero de 2018]. Disponible en: https://rpop. iaea.org/RPOP/RPoP/Content-es/News/relid-cataract-study.htm

3. Agency International Atomic Energy. Proteccion Radiologica de los Pacientes [Internet]. Expresiones utilizadas comúnmente. 2013 [citado 5 de abril de 2018]. Disponible en: https://rpop.iaea.org/RPOP/RPoP/Content-es/InformationFor/ Patients/radiation-terms.htm

4. Jairo Fernando Poveda Bolaños. Determinación de dosis en el cristalino para el personal de intervencionismo y PET-CT del Hospital Pablo Tobon Uribe. 2016. 


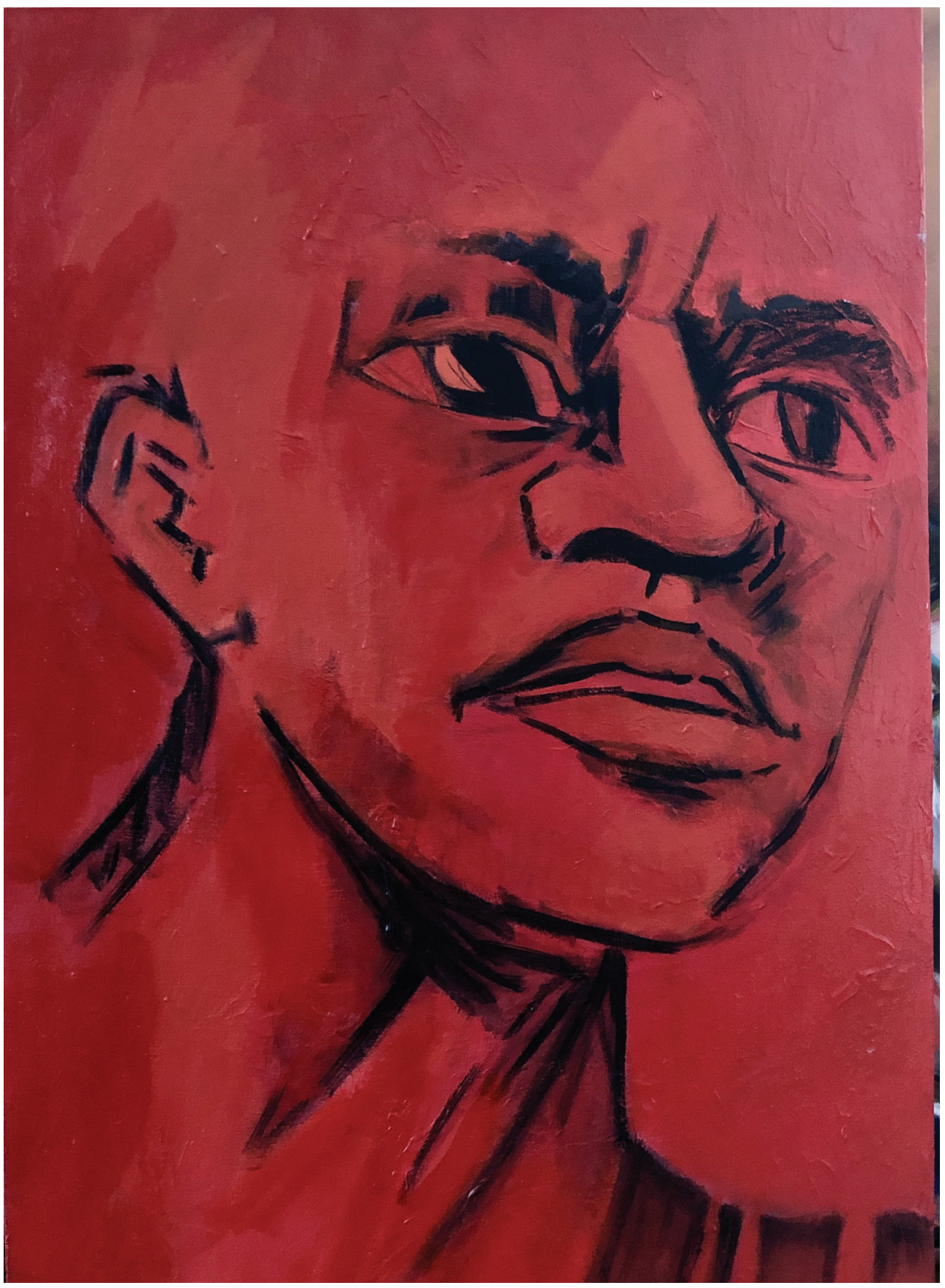

Acrílico sobre lienzo. "Rostros con rastros”, Virginia Aristizábal Parra. 